\title{
Tympanometry is necessary before removing cerumen by syringing with warm water method or prescribing cerumenolytics (softeners) such as glycerin phenol
}

\begin{abstract}
Cerumen removing process is done by variety of methods including Suction, Syringing with warm water, Curette method and so on. In patients who have Tympanic Membrane (TM) perforation and do not aware of it Cerumen may conceal the perforation which Health care practitioner may not see it in Otoscopy. If Softeners such as Glycerin is prescribed for softening theCerumen after pouring softenerpatient will feel true Vertigo and by irrigation with warm water infection will be occurred (Otorrhea) or perforation will be extended. It is clear that Tympanometry in some cases who have Cerumen will be false Type B with Low Ear Canal Volume (ECV) usually ECV lower than 1 or $0.5 \mathrm{cc}$ in adults but in many cases who have Cerumen and Otoscopy is not possible Tympanometry is useful for recording TM mobility. We deal with this subject in this chapter by introducing one case report.
\end{abstract}

Volume 2 Issue 6 - 2015

\begin{abstract}
Alireza Bina, Shahriar Hourizadeh
Atieh Hospital,Audiology Clinic, Iran
\end{abstract}

Correspondence: Alireza Bina,Atieh Hospital,Audiology Clinic, Iran, Tel 817-666-2926,Email bina-alireza@yahoo.com

Received: January 27, 2015 | Published: July 18, 2015

\section{Case report}

A 57years old male patient who wore Hearing Aid unilaterally in left ear referred to our clinic to get Hearing Aid for his right ear. ${ }^{1,2}$ In Otoscopy TM in right ear was normal but in left ear External ear Canal was full of wax (Cerumen) and Otoscopy was not possible. ${ }^{3}$ Cerumen in left ear was probably produced because of wearing Hearing Aid with occluded ear mold. ${ }^{4}$ Tympanometry was performed before referring patient for removing Cerumen. The result was Type A in right ear and Type $\mathrm{B}$ with $\mathrm{ECV}=5 \mathrm{cc}$ in left ear. ${ }^{2,5}$ If Type B were false, ECV should be low but high ECV in left ear indicated perforation. Since large probe cuffs may increase ECV falsely Tympanometry was done again by changing rubber probe cuff for a better diagnosis. Result was not change and ECV with new cuff was still $5 \mathrm{cc}$. After removing Cerumen by suction method vast central perforation was revealed in Otoscopy of left ear. ${ }^{6}$

\section{Conclusion}

Tympanometry is essential before irrigation with warm water method or prescribing softeners such as Glycerin. False Type B with low ECV should be considered but in many cases who have Ceumenin their External ear canalevaluation of TM by Tympanometry is possible. In one study which is done in our clinic we accomplished Tympanometry for 25 patients who had Cerumen in theirboth ears and Otoscopy was not possible. False Type B was seen only in 5 patients and normal Tympanogram (Type A) were recorded for the other patients. In our clinical experience false Type B is more seen in patients who have black Cerumen and less seen in those who have brown.

\section{Acknowledgments}

None.

\section{Conflicts of interest}

Author declares there are no conflicts of interest.

\section{Funding}

Noen.

\section{References}

1. Wilson PL, Roeser RJ. Cerumen management Professional issues and techniques. J Am Acad Audiol. 1997;8(6):421-430.

2. Timothy CH. Ear Wax. American Hearing Research Foundation, Chicago, Illinois. 2012.

3. Oliveira RJ. The active ear canal. J Am Acad Audiol. 1997;8(6):401-410.

4. X Bass EJ, Jackson JF. Cerumen Types in Eskimos. Am J Phys Anthropol. 1977;47(2):209-210.

5. Fraser JG. The efficacy of Wax solvents in vitro studies and a clinical trial. J Laryngol Otol . 1970;84(10):1055-1064.

6. Grossan M. Cerumen removal -Current challenges. Ear Nose Throat J. 1998;77(7):541-546,548. 